\title{
APLICAÇÃO DOS MÉTODOS GEOELÉTRICOS DE ELETRORRESISTIVIDADE E POLARIZACCÃO INDUZIDA NA CARACTERIZAÇÃO DE ANOMALIAS COM DIFERENTES RESOLUÇÕ๊ES.
}

Marcelo Pellicano Falleiros ${ }^{1}$, Welitom Borges Rodrigues ${ }^{2}$, Eduardo Xavier Seimetz ${ }^{3}$, Anna Maria Ferreira Matos Ribeiro de Lara $^{4}$, Nicole Evelyn Carvalho de Oliveira ${ }^{5}$. 1,2,3,4 e 5 - Universidade de Brasília IG UnB.

Copyright 2018, SBGf - Sociedade Brasileira de Geofísica

Este texto foi preparado para a apresentação no VIII Simpósio Brasileiro de Geofísica, Salinópolis, 18 a 20 de setembro de 2018. Seu conteúdo foi revisado pelo Comitê Técnico do VIII SimBGf, mas não necessariamente representa a opinião da SBGf ou de seus associados. É proibida a reprodução total ou parcial deste material para propósitos comerciais sem prévia autorização da SBGf.

\section{Resumo}

O trabalho exibe uma comparação de resultados com diferentes resoluções de investigação geoelétrica utilizando técnicas da eletrorresistividade e polarização induzida (dominio do tempo) na detecção de possíveis aréas que possam apresentar mineralizações auríferas. Os estudos foram desenvolvidos no Garimpo BMM localizado próximo ao município de Nossa Senhora do Livramento - Mato Grosso, Brasil. Os primeiros resultados gerados foram realizados com espaçamento eletródico de 10 metros, em uma segunda campanha foi utilizado espaçamento entre eletrodo de 5 metros. As novas investigações possibilitaram detalhar ainda mais a anomalia observada. A análise dos dados adquiridos com um menor espaçamento corroboraram para determinação de um modelo geofísico-geológico do local. Embora o efeito IP tenha apresentado bons resultados, não foi possível determinar um local potencial para exploração mineral.

\section{Introdução}

Por volta do ano de 1770 ,século XVII, Bandeirantes iniciaram a exploração na região da Baixada Cuiabana, estado do Mato Grosso, em busca de pepitas de ouro. O ciclo do ouro rapidamente apresentou decadência mas no século seguinte houve uma ascensão na região em busca do minério. Naquela época, o ouro era abundante e encontrava-se em aluviões e veios de quartzos aflorantes (Silva et al, 2002).

Os depositos auríferos do Grupo Cuiabá se apresentam como fortes trends estruturais na direção NE-SW, figura 01. A ocorrência de ouro na região encontra-se em agregados de veios de quartzo. O ouro, por sua vez, encontra-se livre ou no interior de piritas contidas nos veios e seus halos hidrotermais que contem monazitas, zircões e calcoperitias em menor quantidade (Barbosa, 2008).

Atualmente, os métodos tradicionais de pesquisas, tais como: sondagens rotativas e geoquímica buscam avaliar o potencial aurífero. Como alternativa a geofísica, como método indireto, vem ganhando espaço nas mineradoras da região por oferecer assinaturas em função da característica do subsolo, e assim, otimizando a explotação das áreas pesquisadas. Dentre os métodos geoelétricos destacam-se, para tal contexo, as técnicas de Polarização Induzida e Resistividade.

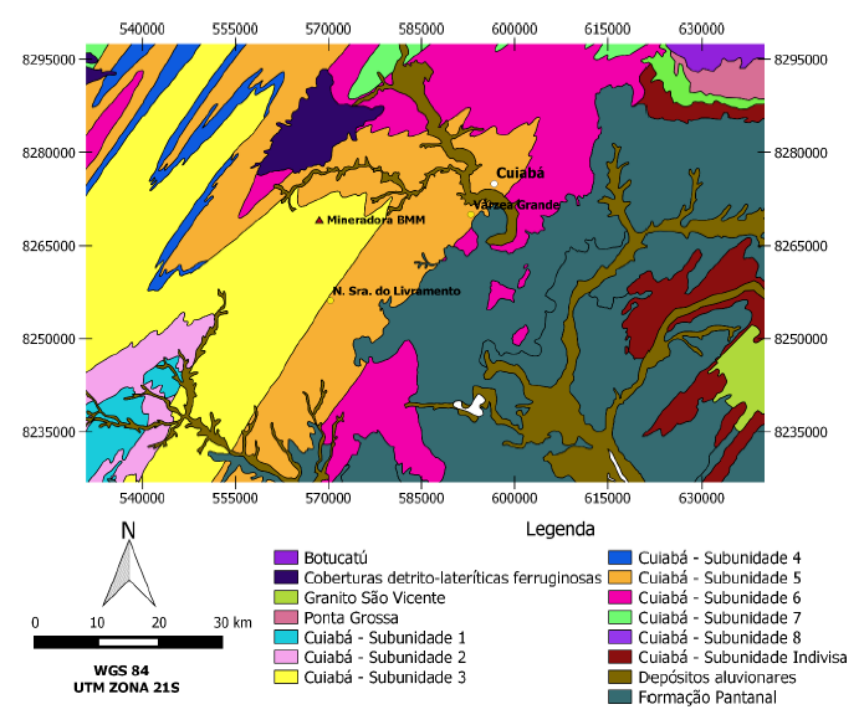

Figura 01 - Mapa Geológico da área da Mineradora BMM (Wernek, 2017).

\section{Metodologia/ Problema Investigado}

A área de estudo esta localizada dentro da área da mineradora Brasil Minério Mineração (BMM) no estado do Mato Grosso próximo a capital Cuiabá no município de Nossa Senhora do Livramento figura 01. O objetivo do trabalho é mostrar a diferença da resolução espacial em pseudo secções de resistividade e cargabilidade dispondo de dados com dois diferentes espaçamentos (10 e 5 metros). E também comparar as melhorias e os efeitos causados no aumento da resolução dos alvos investigados.

Os dados das seções de eletrorresistividade e cargabilidade foram coletados com o resistivímetro Syscal Pro 72 e a modelagem dos dados obtidos foram realizados nos Softweres Prosys e Res2Dinv. Os dados foram coletados utilizando 0 arranjo dipolo-dipolo aplicando a técnica de caminhamento elétrico, figura 02 , em áreas aflorantes com mineralizações previamente conhecidas. Entre as características de cada arranjo deve ser considerado a profundidade de investigação, a sensividade do arranjo para mudanças verticais e horizontais na resistividade de subsuperfície e alcance do sinal (Loke, 2004). Portanto, o arranjo dipolo-dipolo é muito eficiente para registrar grandes efeitos anômalos, mas é suscetível a contaminação por ruído. 
Durante aquisição dos dados, com espaçamento eletrodico de 10 metros, foi utilizado o tempo de 2 e 4 segundos de injeção de corrente elétrica. Para aquisição com espaçamento eletrodico reduzido pela metade o tempo de injeção de corrente foi de 8 segundos. As linhas eram paralelas, figura 02, espaçadas em aproximadamente 50 metros com uma diferença de 30 metros do início de uma linha da outra. Como o subsolo é heterogênio os valores coletados representam uma média ponderada de todas as resistividades do meio por onde a corrente eletrica percorreu.

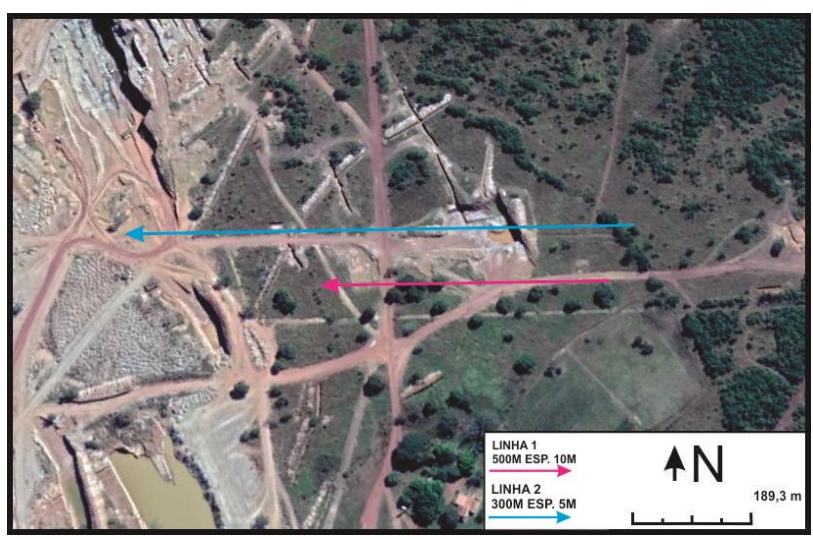

Figura 02 - Localização da área de investigação na mineiradora BMM. Linha 01500 metros espaçamento $10 \mathrm{~m}$, linha 02300 metros espaçamento $5 \mathrm{~m}$.

O método de polariazção induzida consiste em polarizar minerais metálicos induzido por fluxos de corrente elétrica injetadas no solo. Quando a corrente aplicada é desligada, a tensão cai instantaneamente pela quantidade da voltagem, deixando uma tensão residual que decaía com o tempo (Reynolds, 1997). Este método foi medido ,no trabalho em questão, no domínio do tempo, através do decaimento do potencial remanescente após o desligamento da fonte de corrente.

\section{Resultados}

Os dados, Linha 1 figura $\mathbf{0 2}$, adquiridos foram inicialmente importados para o Prosys aonde realizou o processo de filtragem definindo uma escala de valores para cargabilidade e resistividade. Para cargabilidade (m) o resultado variou de 0 a $80 \mathrm{mV} / \mathrm{V}$ e valores de resistividade entre 1,8 e 10.000 ohm.m. Ao importar o dado filtrado para o Res2Dinv foi feita a inversão dos dados com base na função Least Squares Invertion. Por fim, obteve-se os modelos, em forma de pseudo seções, de resistividade e cargabilidade mostrados na figura 03.

Por outro lado, os dados da Linha 2 figura 02, foram adquiridos em outra campanha e cedidos para realização deste trabalho. Do mesmo modo os dados foram filtrados no Prosys e importados para o Res2Dinv. Os valores obtidos de cargabilidade $(\mathrm{m})$ variaram de 0,45 a $283 \mathrm{mV} / \mathrm{V}$ e os de resistividade entre 4,5 a 10.593 ohm.m. Os modelos gerados foram apresentados em forma de pseudo-seções. Com o objetivo de fazer a comparação das linhas foi necessário traze-las para a mesma escala de cor e manter as proporções das escalas verticais e horizontais.

$\mathrm{Na}$ figura $\mathbf{0 3}$ foi circulado dois importantes alvos no que diz respeito ao contraste de propriedade elétrica de resistividade e cargabilidade associados ao potencial de mineralização. Ainda nota-se que há correlação das anomalias nas seções com espaçamento de eletrodo em 10 e $5 \mathrm{~m}$.

A região número 1 , que na seção da Linha 01 se encontra em 360 metros ao longo do perfil, apresenta um baixo valor de resistividade e um alto valor de cargabilidade por volta de 13 metros de profundidade, figura 03. E ainda na seção de cargabilidade observa-se que o corpo anomalo esta restrito, ou seja, não se prolonga do mesmo modo que a rocha com alto valor de cargabilidade, figura 03. Entretanto, este mesmo alvo na Linha 02 não é observado devido ao efeito de dissipação de energia e também a menor resolução das bordas.

$\mathrm{O}$ alvo número 2 , figura $\mathbf{0 3}$, nas seções de resistividade sugerem que há uma falha no local. A seção de cargabilidade da Linha 02 apresenta uma anomalia pontual cerca de 50 metros do início do perfil com profundidade cerca de 6 metros. Essa anomalia propõe que na região da falha possa ter ocorrido uma intrusão hidrotermal possivelmente mineralizada, figura 03.

\section{Discussão e Conclusões}

A comparação de dados de polarização induzida e eletrorresistividade com diferentes resoluções foi fundamental para observar as vantagens e desvantagens e $o$ que é benéfico quando correlacionadas. Os resultados obtidos foram fundamentais para fazer a interpretação da área e diante de dois modelos com diferentes resoluções pode-se gerar um modelo geofísico-geológico da região um pouco mais preciso, figura 4.

Entretanto, após feita a amostragem do material nas zonas sugeridas com o modelo proposto, figura 04 constatou-se que 0 veio sulfetado não estava mineralizado. Wernek, 2017 propôs em seu trabalho que ao utilizar as técnicas de porcentagem de efeito de frequência (PFE) e fator metal (FM) poderia indentificar anomalias com características como alvos principais, alvos secundários e veios não sulfetados.

\section{Agradecimentos}

A Universidade de Brasília (UnB), ao Instituto de Geociências IG, ao LGA (Laboratório de Geofísica Aplicada) e a METAMAT por viabilizar a pesquisa na região.

\section{Referências}

BARBOZA, E. S. 2008. Gênese e controle estrutural das mineralizações Auríferas do Grupo Cuiabá, na Província Cuiabá - Poconé, centro Sul do Estado de Mato Grosso - Brasil. Tese (Doutorado)- Universidade do Estado do Rio. 
BRAGA, A. C. O. (1997). Métodos geoelétricos aplicados na caracterização geológica e geotécnica - formações Rio Claro e Corumbataí, no município de Rio Claro-SP. Tese de Doutorado, Instituto de Geociências e Ciências Exatas, UNESP, Campus de Rio Claro-SP, 173p.

LOKE, M. H. (2004). A practical guide to 2-D and 3-D surveys. Electrical imaging surveys for environmental and engineering studies. p. 2, 5 e 24

REYNOLDS, J. M. An introduction to Applied and Environmental Geophysics. Ed. John Wiley and Sons. 796 p. 1997. West Sussex, England.

SILVA, C. H., SIMÇÕES, L. S. A., RUIZ A. S. 2002. Caracterização estrutural dos veios auríferos da região de Cuiabá, MT. ra et al. (06 co-authors), 1999. 2D geoelectrical model for the Parnaíba conductivity anomaly, north-northeast Brazil and its tectonic implications. Tectonophysics, 302: 57-69.

WERNECK, B. K., Aplicação de Eletrorresistividade e IP na Prospecção de Depósitos Auríferos na Região de Nossa Senhora do Livramento - MT. Curso de Graduação em Geofísica (Trabalho de Conclusão de Curso), IG/UnB, 53p, 2017. 


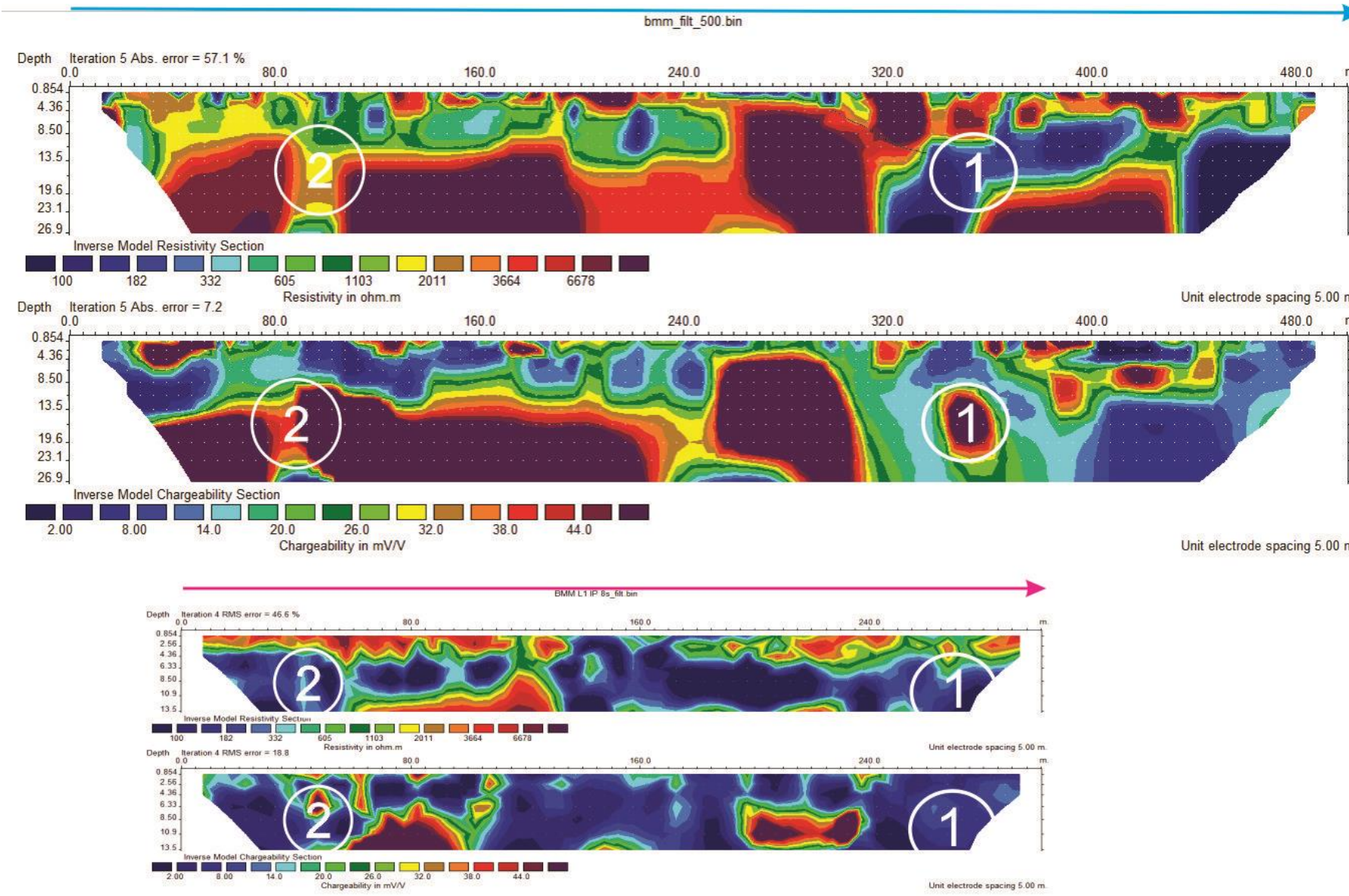

Figura 03 - Linha 01 e Linha 02 com espaçamento de 10 e 5 metros respectivamente. Seções de resistividade e cargabilidade.

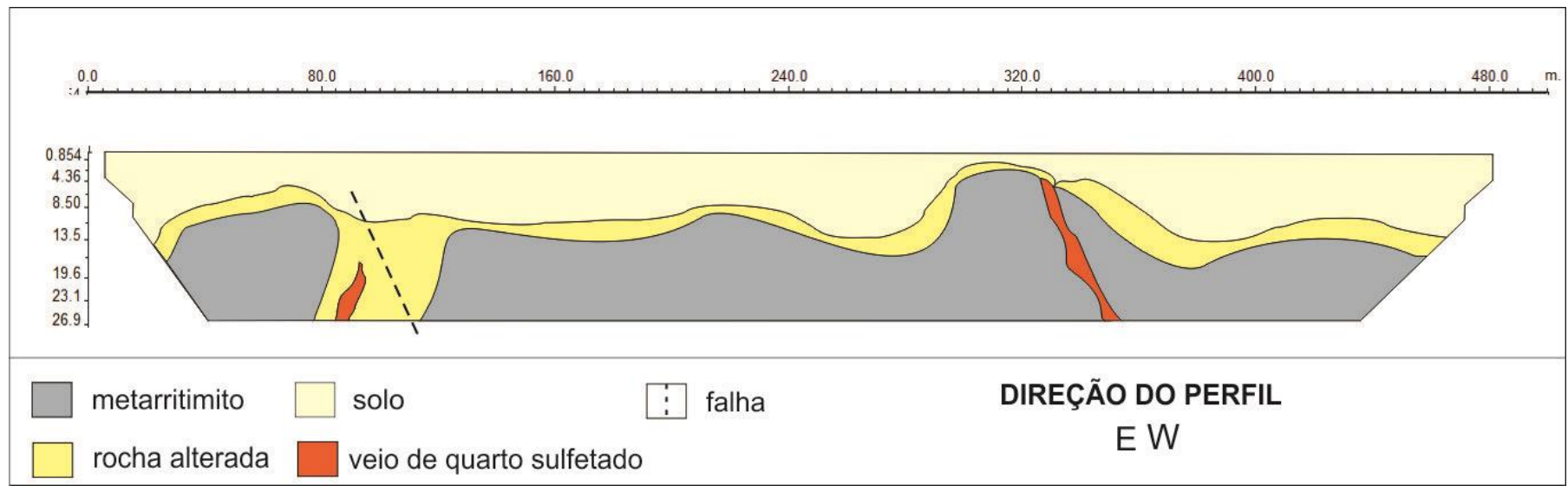

Figura 04 - Modelo geofísico-geológico, (Modificado de Wernek, 2017). 